\title{
Bench Scale Test of a New Ironmaking Process with Mixture of Iron Ore Concentrate and Pulverized Coal
}

\author{
Hongyu GOU, Wei-Kao LU and Czeslaw BRYK ${ }^{1)}$ \\ Department of Materials Science and Engineering, McMaster University, Hamilton, Ontario, L8S 4L7, Canada. \\ 1) Formerly McMaster University. Now at Dofasco Inc., Hamilton, Ontario, L8N 3J5, Canada.
}

(Received on November 20, 1991; accepted in final form on March 19, 1992)

\begin{abstract}
A new metallurgical reactor called the LB Furnace is currently being developed at McMaster University. A series of experiments on ironmaking was conducted successfully in a laboratory bench scale furnace. Sponge iron and hot metal were produced with desired properties by using mixture of iron ore concentrate and pulverized coal. Compositions of hot metal (except carbon) and slag produced are similar to those of the blast furnace products. The carbon content of the hot metal can be effectively controlled in the range of 0.3 to $4.0 \%$. Sponge iron can be produced with different degrees of metallization, up to $99 \%$. The unique design of the reduction unit of the LB Furnace has achieved its goals: (1) the direct use of iron ore concentrate and pulverized coal, (2) the intensive reduction reactions $(15 \mathrm{~kg} \mathrm{Fe} / \mathrm{hr}$ throughput in a $8.3 \mathrm{~cm}$ reduction tube of $75 \mathrm{~cm}$ long, or 88 tonne $\mathrm{Fe} / \mathrm{d} / \mathrm{m}^{3}$ of the reduction tube inner volume), and (3) the complete combustion of the gaseous reduction products in one single reactor for high energy efficiency.
\end{abstract}

KEY WORDS: ironmaking; LB Furnace; smelting reduction; sponge iron.

\section{Introduction}

Along with innovations for the improvement of the blast furnace ironmaking process, development of the smelting reduction processes in which the molten iron is produced without using coke, has been promoted intensively during the last two decades. The main interests are in overcoming the major shortcomings associated with the blast furnace process, such as anticipated shortage of coking capacity and new environmental regulations, and limited flexibility in raw material properties and production levels. Most smelting reduction processes are based on coal-electricity or coal-oxygen as the sources of energy and reductant, and mainly consist of a pre-reduction unit and a melting and final reduction unit. ${ }^{1)}$ Great efforts in this direction at pilot plant scale are being made in Japan, ${ }^{2)}$ United States ${ }^{3)}$ and Australia ${ }^{4)}$ and at commercial scale in south Africa. ${ }^{5)}$ The development of the LB Furnace process at McMaster University is aimed for a smelting reduction reactor of high energy efficiency and high productivity.

The fundamental development of the process was based on the following principles ${ }^{63}$ :

- the iron ore and coal should be directly used as fines, not only to save the cost of agglomeration and carbonization, but also to overcome the reaction kinetic barrier for mass transfer and chemical reaction in reduction,

- coal should be used as the reductant as well as the energy source to result in the form of $\mathrm{CO}_{2}$ and $\mathrm{H}_{2} \mathrm{O}$ in a single reactor to achieve high energy efficiency and low coal rate, and

- the kinetics of reduction in the mixture of fine ore and coal will be mainly controlled by heat transfer and heat supply, therefore, the limiting value of the productivity per unit volume of reactor could be greatly enhanced.

In 1982 to 1984 , some preliminary experiments were conducted by Lu and Bryk ${ }^{7,8}$ to establish the basis for a new furnace design, and the process was then named with the first letter of these two inventor's names. Since 1984, a series of experiments were carried out in a laboratory bench scale furnace. The main concerns at that time were to assess the technical feasibility of the process and to establish the sensitivities of the process to the variations of operating parameters. Experimental results from this bench scale furnace were very encouraging. Sponge iron and liquid hot metal were produced successfully with higher energy efficiency, lower coal consumption, and higher productivity in comparison with the current ironmaking processes.

This paper will present some experimental results for making sponge iron and hot metal in the bench scale LB Furnace. The mass and thermal balance analysis based on experimental results will also be discussed.

\section{Process Description}

The detailed description of the furnace development can be found in the literatures. ${ }^{9,10}$ The sketch of the first bench scale LB Furnace is shown in Fig. 1. 


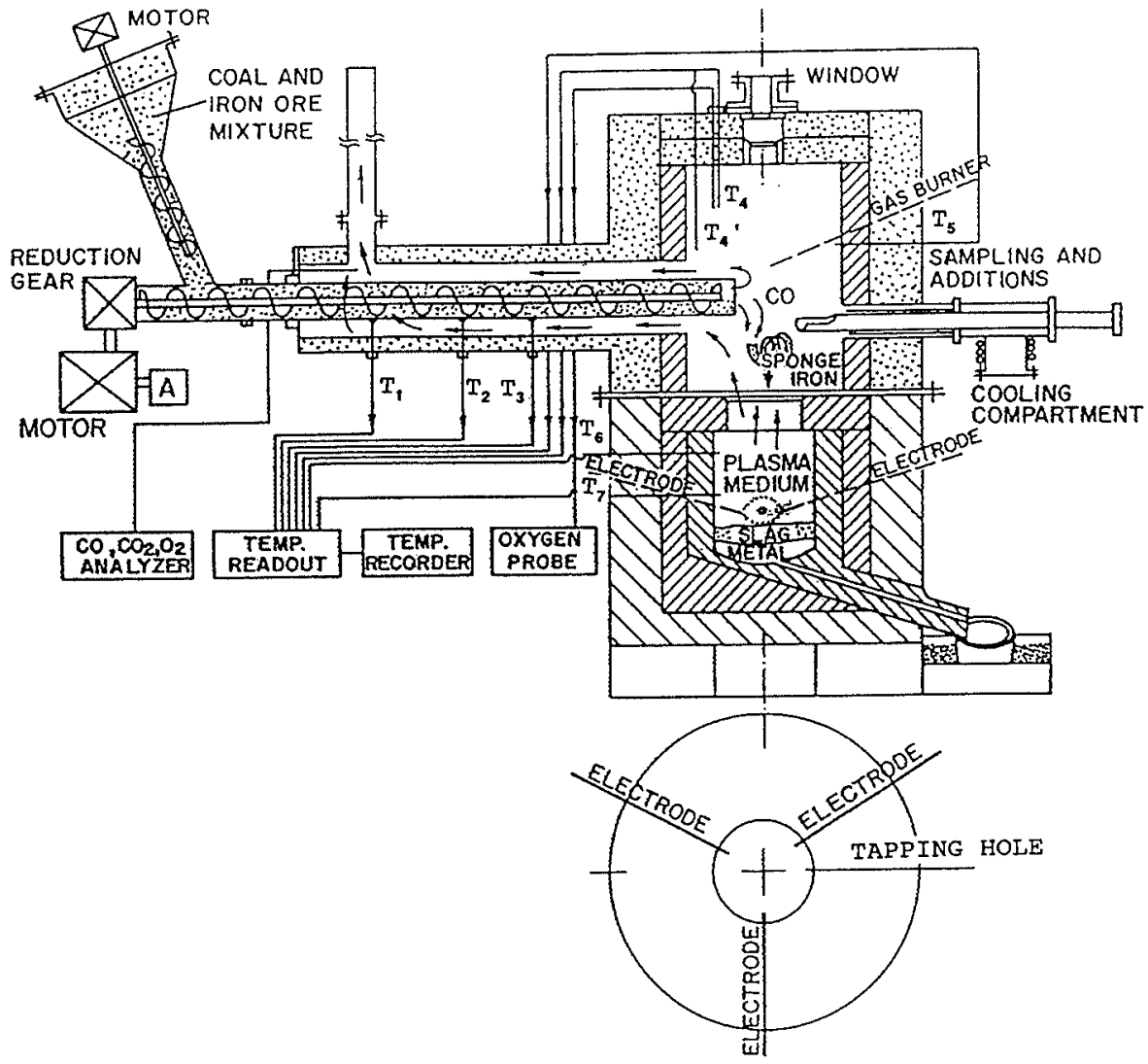

Fig. 1.

A sketch of the bench scale LB Furnace

$T_{i}$ 's: thermocouple.

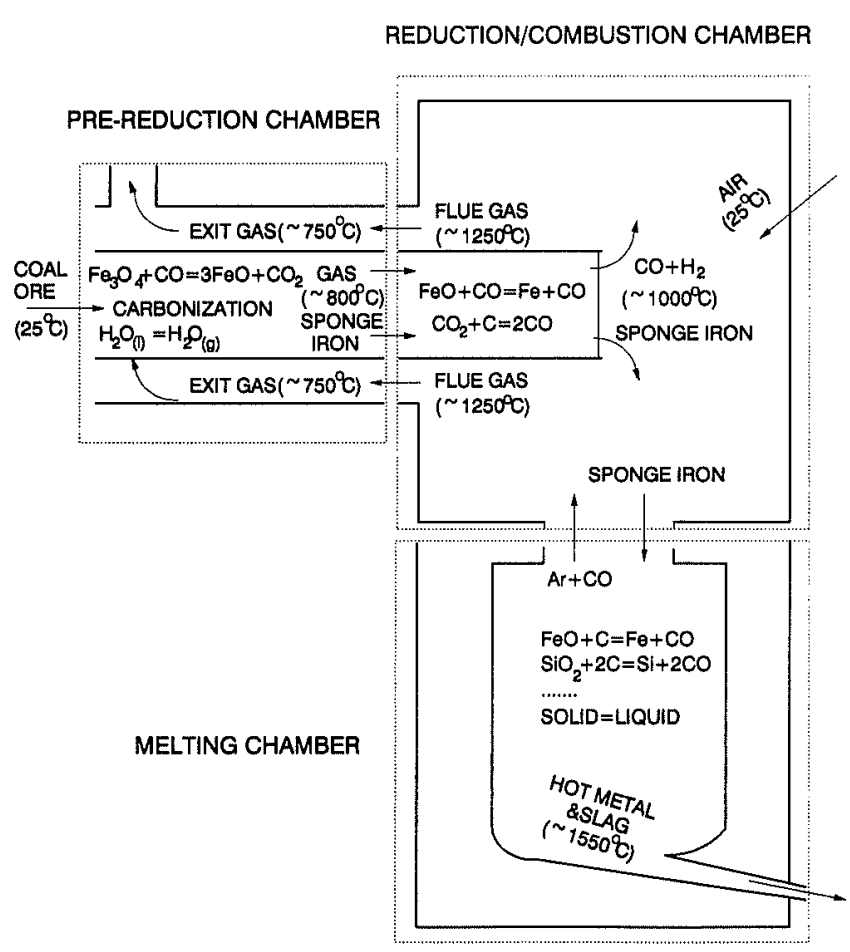

Fig. 2. Division in the LB Furnace and the major reactions for ironmaking in each chamber.

The LB Furnace can be divided into three chambers, i.e. the pre-reduction chamber, the reduction/combustion chamber and the melting chamber. The division and the corresponding major reactions for ironmaking in each chamber are shown in Fig. 2.

In the pre-reduction chamber, through a silicon carbide reduction tube, a stainless steel screw feeder moves the mixture of iron ore concentrate and pulverized coal into the furnace. The reduction tube extends from the charging end through the prereduction chamber to the reduction/combustion chamber.

Gases generated inside the reduction tube by chemical reactions flow co-currently with the solid reacting mixture and enter the reduction/combusion chamber at the discharging end of the tube. Air is introduced into the chamber through the air inlets at ambient temperature. Combustion of the gaseous reduction products and oxygen in the air takes place in the chamber as heat source in the system. Intensive heat transfer from the high temperature flame to the reduction tube and the reacting mixture inside the tube occurs in this chamber.

The flue gas leaves the reduction/combustion chamber through the annulus outside of the reduction tube in the pre-reduction chamber and transfers heat to the mixture inside the tube through the tube wall.

The sponge iron drops to the melting chamber where heat is supplied by a plasma, generated with argon flowing through three hollow electrodes. The liquid hot metal and slag are tapped out through a tapping hole.

\section{Characteristics of LB Ironmaking Process}

In the pre-reduction chamber of the LB Furnace, the mixture is heated up and several reactions may take place, i.e. evaporation of moisture, de-volatilization of coal, pre-reduction of iron oxides to wustite by volatile matter, and to a very limited extent, metallization of wustite.

The reduction of iron oxide continues at a higher rate upon entering the reduction/combustion chamber 
where the higher rate of heat transfer results in a higher temperature in the reacting mixture. The reduction is also enhanced due to the intensified solution loss reaction:

$$
\mathrm{C}+\mathrm{CO}_{2}=2 \mathrm{CO}
$$

or

$$
\mathrm{C}+\mathrm{H}_{2} \mathrm{O}=\mathrm{H}_{2}+\mathrm{CO},
$$

which takes place in the mixture between local residual carbon and $\mathrm{CO}_{2}$ and $\mathrm{H}_{2} \mathrm{O}$ to maintain a strong reducing atmosphere.

The final reduction of the residual oxides and the formation of the liquid hot metal and slag are completed in the melting chamber. The electric energy is used here for convenience in the laboratory, and this last step of the process may be carried out by charging the lumps of sponge iron to a stirred metal bath.

The amount and the reducing power of the gaseous reduction product increase along the way inside the reduction tube from the low temperature region to the high temperature end, because more chemical reactions, including the solution loss reaction, become active. It should be pointed out that in the reduction tube, there is no involvement of air; the gas generated in the tube contains practically no nitrogen, and therefore, produces a strong reducing atmosphere.

Despite the strong oxidation atmosphere resulting from the complete combustion in the reduction/combustion chamber, the reoxidation of the sponge iron in the system was proven to be insignificant. The reducing gaseous products flowing out of the reduction tube adequately protect the sponge iron from re-oxidation when the sponge iron is pushed out off the reduction tube and exposed to the oxidizing flame.

In a system of large interfacial contact and relatively small mass transfer resistance, such as in the mixture of iron ore concentrate and pulverized coal, the overall kinetics of strongly endothermic reactions would be mainly limited by heat supply to the reaction front. ${ }^{11)}$ To maintain fast chemical reaction rate and high productivity requires intensive heat transfer.

Generally speaking, the reduction/combustion chamber is the strategic point in the process to control heat generation and promote heat transfer, ${ }^{12)}$ and in turn, to promote energy efficiency and productivity.

\section{Experimental Results}

\subsection{Raw Materials}

Table 1 shows chemical compositions of the magnetite concentrates and proximate analyses of the high volatile coals which have been used in the experiments. The particle size of the iron ore concentrate is $-75 \mu \mathrm{m}$. The coal has to be ground and screened to $-150 \mu \mathrm{m}$. No noticeable difference on the reduction rate has been observed due to different types of concentrate or coal. $^{7,8)}$

The iron ore concentrate and pulverized coal were mixed according to the pre-determined coal/ore ratio, in the range from $16 / 84$ to $30 / 70$ by weight.
Table 1. Chemical analyses of raw materials. (wt \%)

I. Iron ore concentrates

\begin{tabular}{ccccccccc}
\hline Ores & $\mathrm{Fe}_{\mathrm{T}}$ & $\mathrm{SiO}_{2}$ & $\mathrm{CaO}$ & $\mathrm{MnO}$ & $\mathrm{MgO}$ & $\mathrm{Al}_{2} \mathrm{O}_{3}$ & $\mathrm{~K}_{2} \mathrm{O}$ & $\mathrm{S}$ \\
\hline $\mathrm{A}$ & 66.70 & 5.27 & 0.28 & 0.013 & 0.013 & 0.58 & 0.18 & 0.009 \\
B & 67.79 & 5.07 & 0.06 & 0.35 & 0.05 & 0.35 & 0.02 & 0.01 \\
\hline II. Coals & & & & & & \\
\hline
\end{tabular}

\subsection{Experimental Apparatus}

The inner diameter of the reduction tube is $8.3 \mathrm{~cm}$. The length of the tube is $75 \mathrm{~cm}$ and the part which is extended inside the reduction/combustion chamber is about $16 \mathrm{~cm}$. The inner volume of the reduction/combustion chamber is $0.06 \mathrm{~m}^{3}$. The inner volume of the melting chamber is 0.02 and $0.005 \mathrm{~m}^{3}$ underneath the electrodes, corresponding to a maximum capacity of holding $15 \mathrm{~kg}$ hot metal and associated slag. Opposite to the reduction tube exit, a sampler may be pushed into the reduction/combustion chamber to catch falling pieces of sponge iron for chemical analysis.

In the pre-reduction chamber, there are three thermocouples located along the annulus for measuring the fiue gas temperatures. Three thermocouples are installed in the reduction/combustion chamber and two in the melting chamber. Gas samples were taken immediately before the gas entered the chimney for the analysis of $\mathrm{CO}$ and $\mathrm{CO}_{2}$ by two infrared analyzers, and $\mathrm{O}_{2}$ by a magnetic analyzer. The total iron, metallic iron and ferreous iron of sponge iron samples were determined by the reduction-oxidation titration and carbon was determined with a gasometric analyzer. Hot metal samples were analyzed by an emission spectrometer and slag compositions were determined by an X-ray fluorescence analyzer.

\subsection{Experimental Procedures}

The LB Furnace is operated with continuous charging and intermittent tapping. For experiments reported here, each run stopped with tapping.

At the beginning of an experiment, a natural gas burner was used to heat up the furnace. When the temperature in the reduction/combustion chamber reached about $1200^{\circ} \mathrm{C}$, the feeding of the mixture started. At the commencement of coal/ore reactions which produce $\mathrm{H}_{2}$ and $\mathrm{CO}$, gas analyzers would indicate an increase in $\mathrm{CO}$ content and a decrease in $\mathrm{CO}_{2}$. The natural gas flow was cut back to zero in steps and the air flow was simultaneously adjusted to the required values. As the sponge iron started dropping to the melting chamber, the plasma was turned on to the maintain the melting chamber at above $1600^{\circ} \mathrm{C}$ temperature.

In most experiments, flux (limestone or lime) was added to the melting chamber directly through the sampling port. 


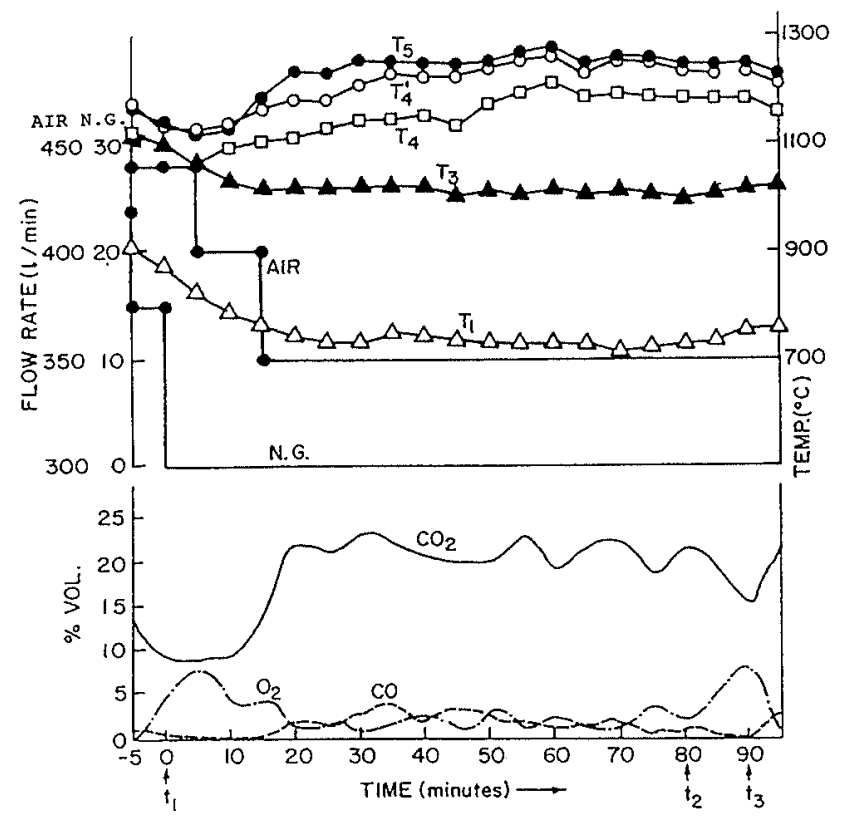

Fig. 3. The progress of a typical experiment in terms of temperature measurement and chemical analysis of exit gas. $t_{1}$ : start feeding mixture; $t_{2}$ : stop feeding mixture; $t_{3}$ : tapping.

Table 2. Experimental conditions.

\begin{tabular}{ccccc}
$\begin{array}{c}\text { Coal/Ore } \\
\text { ratio }\end{array}$ & $\begin{array}{c}\text { Mixture } \\
\mathrm{kg} / \mathrm{hr}\end{array}$ & $\begin{array}{c}\text { Air } \\
\mathrm{cm} / \mathrm{min}\end{array}$ & $\begin{array}{c}\text { Flow rate } \\
\mathrm{Nm}^{3} / \mathrm{hr}\end{array}$ & $\begin{array}{c}\text { Productivity } \\
\text { Hot metal } \\
\mathrm{kg} / \mathrm{hr}\end{array}$ \\
\hline $16 / 84-30 / 70$ & $4-30$ & $4.1-21.5$ & $5.0-33.5$ & $2.0-15.0$ \\
\hline
\end{tabular}

The experiment was terminated by tapping. Before tapping, feeding of the mixture was stopped and the air flow was cut off.

The process of a typical experiment in terms of temperatures at a few points (the locations where the temperatures were taken are shown in Fig. 1), flow rates of natural gas and air, and the exit gas composition, is shown in Fig. 3.

\subsection{Experimental Conditions}

The experimental conditions were selected to examine the effect of operating parameters such as coal/ore ratio in the mixture, mixture feed rate, and excess air ratio on the furnace productivity, energy consumption, and properties of the products. Table 2 lists the ranges of the main experimental conditions. The values of the charging rate, the flow rate of air, and the productivity are based on the time-averaged quantities during the steady state operation.

\subsection{The Reaction Products}

\subsubsection{Sponge Iron}

Several runs were interrupted during the steady state operation. Right after the air input and the mixture feed was stopped, the reduction tube with the screw in place was withdrawn partly from the furnace and $\mathrm{N}_{2}$ was introduced into the tube to accelerate the cooling of the mixture and inhibit the re-oxidation of the sponge iron by oxygen in the atmosphere. When the tube was

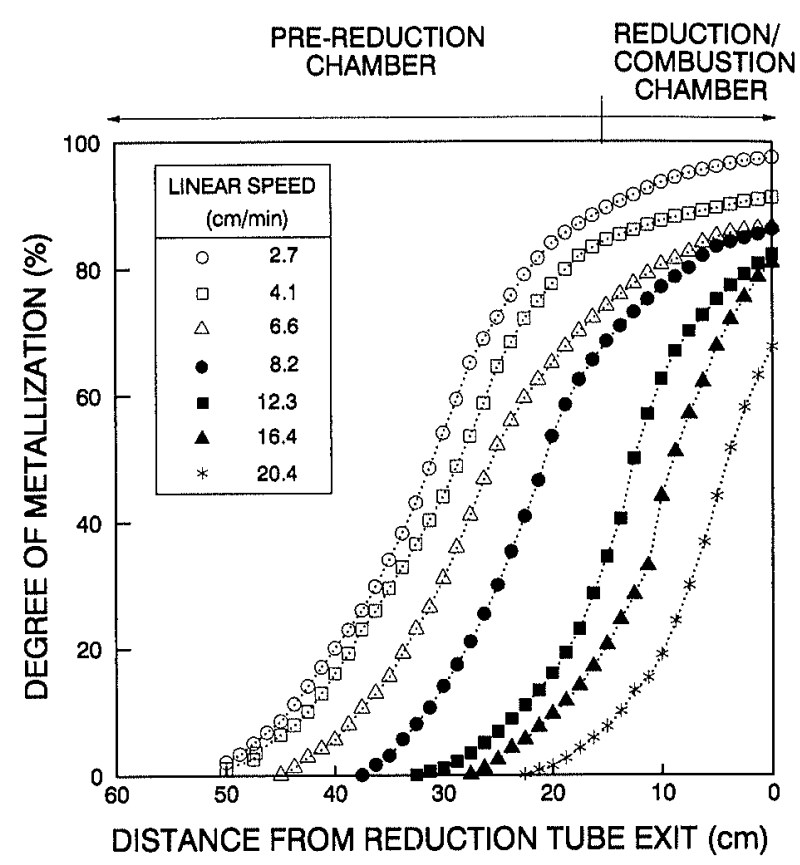

Fig. 4. Progress of reduction inside the reduction tube for different mixture feed speeds.

cooled to room temperature, it was carefully removed, leaving the sponge iron suspended around the screw. Samples were then taken along the axial and radial directions, and spatial dependence of the degree of reduction was determined from chemical analysis of these samples. Some of these data are presented in Fig. 4, where the degree of metallization is defined as:

$$
R_{m}=\frac{\mathrm{Fe}_{\text {metallic }}}{\mathrm{Fe}_{\text {total }}} \times 100 \%
$$

Figure 4 shows the degree of metallization changes along the axial direction for the different mixture feed rates. It is clear that in all the mixture feed rates conducted, the metallization of iron oxides within the mixture did not occur until approximately 20 to $30 \mathrm{~cm}$ along the reduction tube from the charging end. After that, the metallization proceeded slowly for the next $5-10 \mathrm{~cm}$. At this point the metallization occurred rapidly up to about $80 \%$ where the reduction rate fell off to a low value.

It can be seen from Fig. 4 that when the mixture moves slowly in the reduction tube, the beginning of matallization as well as the steep increase in the degree of metallization take place closer to the charging end and most rduction occurs in the pre-reduction chamber with a higher final degree of reduction. A higher feed rate shifts the event towards the discharging end with a lower final degree of reduction. When the linear speed is higher than $12 \mathrm{~cm} / \mathrm{min}$ or the charging rate exceeds $10 \mathrm{~kg} \mathrm{Fe} / \mathrm{hr}$, most reduction takes place inside the reduction/combustion chamber.

The effort of sampling the sponge iron at the tube exit by using the sampler during operation was not very successful due to difficulties in positioning the sampler in the high temperature flame at the right location to catch the falling lumps. Only a few sponge iron samples caught were considered to be sufficiently protected 


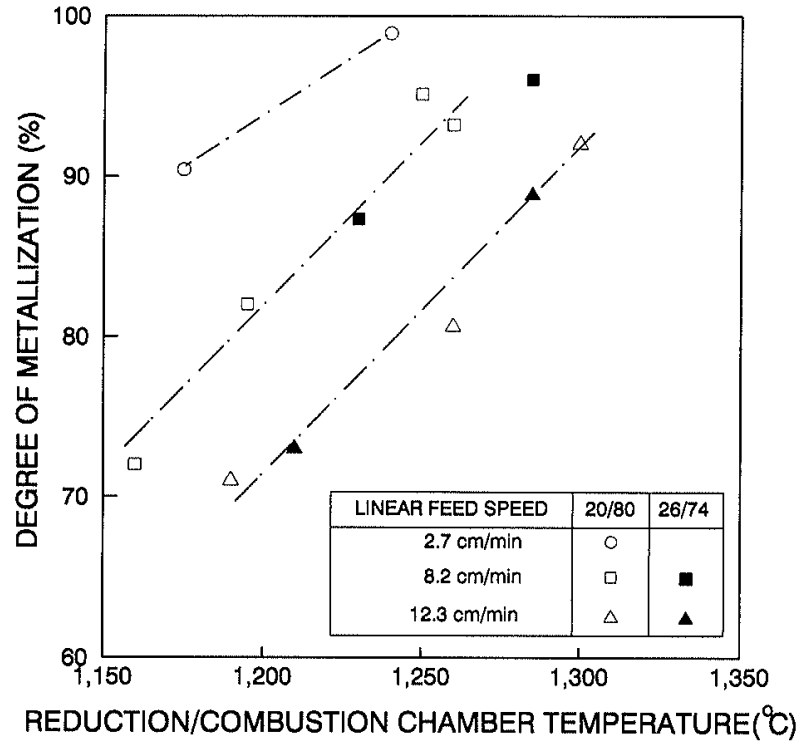

Fig. 5. Influences of the reduction/combustion temperature and the mixture feed speed on the degree of metallization of sponge iron.

from oxidation by furnace atmosphere during sampling, and worthy of analysis. The relationship between the degree of metallization of the sponge samples and the corresponding temperature $T_{4}$, as a representative of the reduction/combustion chamber temperature, is presented in Fig. 5.

This figure shows the significant influence of the chamber temperature on the reduction rate. For example, at coal/ore ratio of $20 / 80$ and feed rate of 12.3 $\mathrm{cm} / \mathrm{min}$, the degree of metallization of the sponge iron varied from $92 \%$ (at $T_{4}=1300^{\circ} \mathrm{C}$ ) to $69 \%$ (at $T_{4}=$ $1190^{\circ} \mathrm{C}$ ). More systematic experiments in crucibles and in an electrical tubular furnace have shown the same strong dependence of degree of metallization on the furnace temperature. ${ }^{7,8,13)}$

From Fig. 5, it is clear that at the same coal/ore ratio, the degree of metallization increases with the decrease of linear velocity or the increase of resident time. At the lowest speed used $(2.7 \mathrm{~cm} / \mathrm{min})$, the sponge iron reached $98.9 \%$ metallization. For the linear speeds conducted, the beneficial effect of higher coal/ore ratio on the kinetics of reduction, when the ratio is higher than 20/80, becomes insignificant.

\subsubsection{Hot Metal and Slag}

The carbon content in the hot metal produced in the LB Furnace is essentially determined by two factors, i.e. the coal/ore ratio in the mixture and the feed rate. By controlling these variables, hot metal of 0.3 to $4.0 \%$ carbon were produced accordingly. As a function of the coal/ore ratio, the carbon contents in the hot metal are presented in Fig. 6. The dependence of the carbon content on feed rate is shown in Fig. 7. From these two figues it is clear that additional carbon added to the mixture and/or increase in feed rate yields a higher carbon content within the metal, and the influence of coal/ore ratio on carbon content in the metal is much more significant than the feed rate.

Figures 8 and 9 give the silicon and sulphur contents

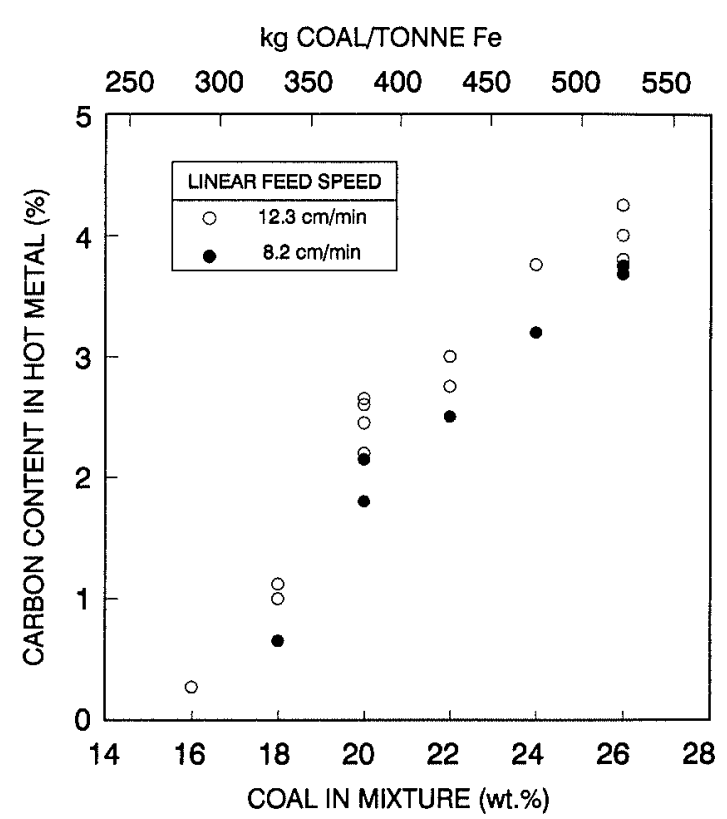

Fig. 6. Effect of coal in the mixture on carbon content in hot metal.

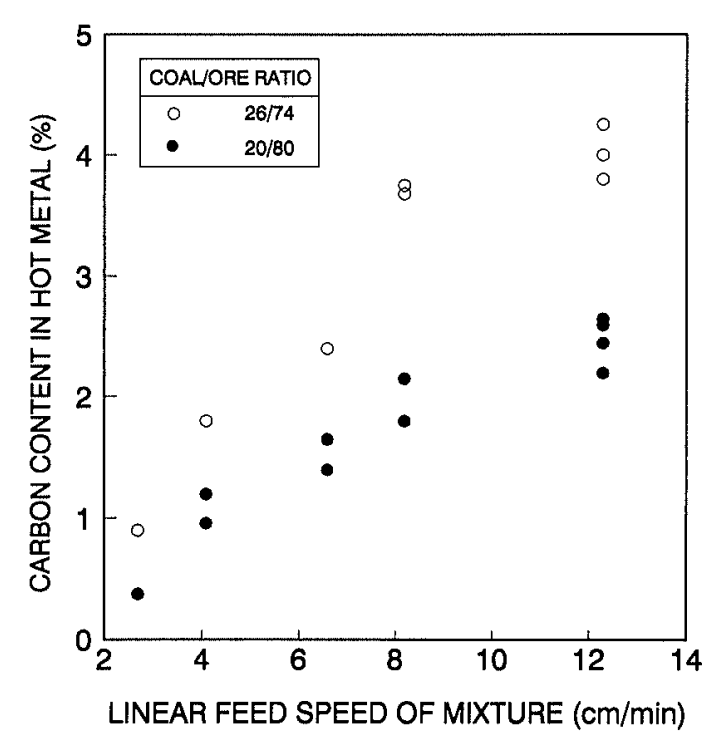

Fig. 7. Effect of mixture feed speed on carbon content in hot metal.

in the hot metal vs. the basicity of the slag, $B$, which is defined in wt $\%$ as:

$$
B=\frac{\mathrm{CaO}+\mathrm{MgO}}{\mathrm{SiO}_{2}+\mathrm{Al}_{2} \mathrm{O}_{3}}
$$

The relationship between silicon content in hot metal and $\mathrm{FeO}$ content in slag is shown in Fig. 10.

Bacause of the lack of gas-solid counter-current flows in the melting chamber of the LB Furnace, the mechanism of silicon reduction via vapour species $\mathrm{SiO}$ as in the case of blast furnace is unlikely to be significant. The most likely mechanism for silicon and sulphur transfer would be by slag-metal reactions in the melting chamber. Due to the uncertainty in temperature measurements of the slag and metal, a quantitative analysis based on the thermodynamic relation of silicon and sulphur behaviour in the slag/metal system can not 


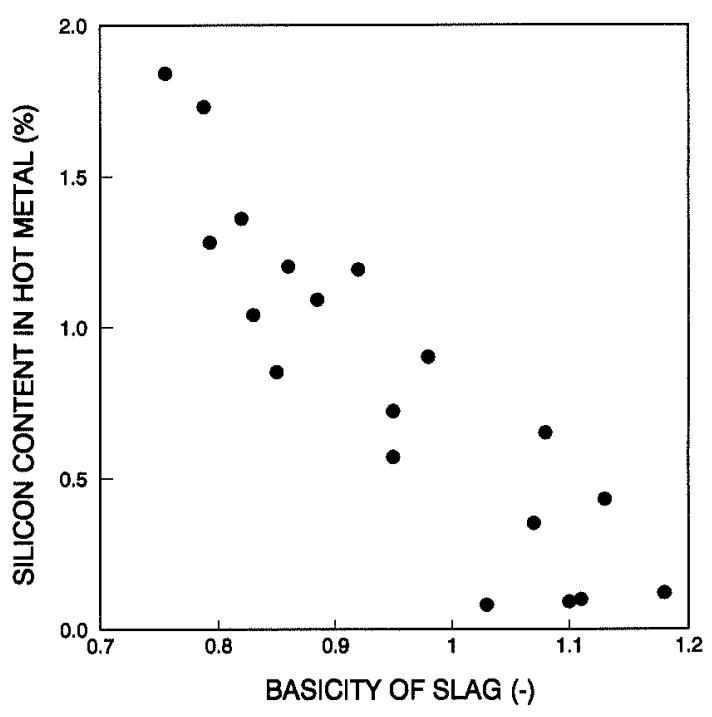

Fig. 8. Relationship between basicity of slag and silicon content in hot metal.

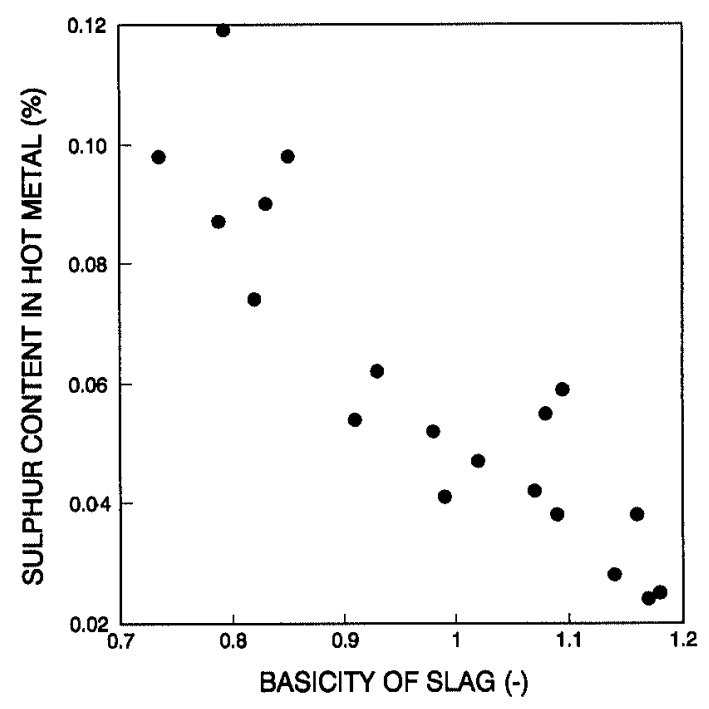

Fig. 9. Relationship between basicity of slag and sulphur content in hot metal.

be justified. In the experiment, the slag basicity was varied in a wide range by adjusting the flux additions. High basicity means low activity of silica in the slag which would result in less silicon reduced to the metal as shown in Fig. 8. Similar interpretation can also be applied to Fig. 9 for the variation of sulphur content in the metal with the slag basicity. At the same feed rate, a lower coal/ore ratio in the mixture generally corresponds a higher $\mathrm{FeO}$ in the slag and a lower carbon in the metal, which in turn, implies a higher oxygen potential in the metal. This explains the decrease of silicon content in the metal with the increase of $\mathrm{FeO}$ in the slag as shown in Fig. 10.

The slag composition of the LB Furnace is similar to that of the blast furnace except for a higher $\mathrm{FeO}$ content. The high $\mathrm{FeO}$ content in slag suggests that the slag is far from equilibrium with the metal phase which is likely caused by poor mixing in the slag/metal pool in the melting chamber. ${ }^{9)}$ It should be noted that with adequate stirring, e.g. bubbling gas through the

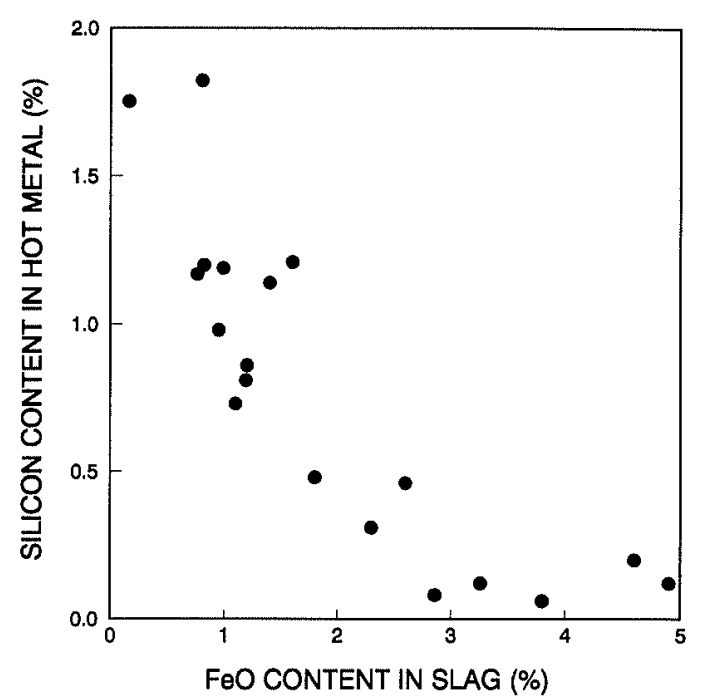

Fig. 10. Relationship between iron oxide content in slag and silicon content in hot metal.

bottom, besides lowering the $\mathrm{FeO}$ content in the slag, the controlling of sulphur and silicon should become more effective.

\subsubsection{Exit Gas}

From Fig. 3, it can be seen that under the supposedly steady state operation, the exit gas temperature varies in the range of $700-800^{\circ} \mathrm{C}$, and the $\mathrm{CO}_{2}$ content is about $22 \%$. If thermodynamic equilibrium were reached, $\mathrm{CO}$ and $\mathrm{O}_{2}$ of any significant amounts could not co-exist in the gas. However, the chemical analysis has shown to be the case as in Fig. 3 which indicates that the mixing in the reduction/combustion chamber was not adequate and this aspect is discussed in detail in the reference. ${ }^{10)}$

Even through the raw materials are initially in powder form, because the sponge iron is in the form of sintered lumps as it is discharged through the flowing gas, there was neither noticeable dust deposit on the tube, nor anywhere along the path of the gas fiow. The sulphur content in the exit gas is barely detectable at the limit of the instrument which is a few ppm of $\mathrm{SO}_{2} \cdot{ }^{8)}$

\section{Mass and Heat Balance}

\subsection{Mass Balance}

The compositions of the raw materials used in mass and heat balance are those of the iron ore A and coal B as shown in Table 1.

In the experiment, the amount of air input varied over a wide range. Three cases of relevance to the experiment are presented here to illustrate an important parameter, the excess air coefficient which is defined based on the volumetric flow rate as:

$$
A_{e x}=\frac{V_{a}}{V_{a, s t}},
$$

where $V_{a}$ is the air flow rate actually used in combustion, and $V_{a, s t}$ is the air flow rate needed in stoichiometry for complete combustion.

The hot metal composition used in mass balance is the typical experimental results with coal/ore ratio of 
Table 3. Typical hot metal composition. (wt \%)

\begin{tabular}{cccccc}
\hline \multicolumn{5}{c}{ Element (\%) } & \\
$\mathrm{Fe}$ & $\mathrm{Si}$ & $\mathrm{Mn}$ & $\mathrm{P}$ & $\mathrm{S}$ & $\mathrm{C}$ \\
\hline 98.69 & 0.25 & 0.01 & 0.02 & 0.03 & 1.00 \\
\hline
\end{tabular}

Table 4. Computed slag composition. (wt\%)

\begin{tabular}{lllllllllll}
\hline $\mathrm{FeO}$ & $\mathrm{SiO}_{2}$ & $\mathrm{Al}_{2} \mathrm{O}_{3}$ & $\mathrm{CaO}$ & $\mathrm{MgO}$ & $\mathrm{TiO}_{2}$ & $\mathrm{Na}_{2} \mathrm{O}$ & $\mathrm{K}_{2} \mathrm{O}$ & $\mathrm{P}_{2} \mathrm{O}_{5}$ & $\mathrm{~S}$ \\
\hline 2.00 & 35.94 & 6.28 & 39.69 & 0.03 & 0.13 & 0.30 & 0.39 & 0.04 & 1.15 \\
\hline
\end{tabular}

Table 5. Computed exit gas composition. (vol\%)

\begin{tabular}{ccccccccc}
\hline Case & $A_{e x}$ & $\mathrm{CO}_{2}$ & $\mathrm{CO}$ & $\mathrm{N}_{2}$ & $\mathrm{H}_{2} \mathrm{O}$ & $\mathrm{O}_{2}$ & $\mathrm{Ar}$ & Total \\
\hline A & 0.92 & 21.48 & 2.62 & 57.77 & 11.09 & 0.00 & 6.71 & 100.00 \\
B & 1.08 & 22.00 & 0.00 & 61.29 & 10.35 & 1.28 & 5.08 & 100.00 \\
$\mathrm{C}$ & 1.48 & 16.63 & 0.00 & 63.12 & 8.48 & 5.43 & 6.43 & 100.00 \\
\hline
\end{tabular}

Table 6. Mass balance (coal/ore $=20 / 80$ ) kg/THM.

\begin{tabular}{llrrr}
\hline \multicolumn{1}{c}{ Items } & Case A & Case B & Case C \\
\hline Exc. air coef. & 0.92 & 1.08 & 1.48 \\
\hline \multirow{2}{*}{ Input: } & Iron ore & 1465 & 1464 & 1465 \\
& Coal & 366 & 366 & 366 \\
& Air & 2177 & 2565 & 3498 \\
& Argon* & 272 & 229 & 378 \\
& CaO & 85 & 85 & 85 \\
& MgO & 25 & 25 & 25 \\
\hline \multirow{2}{*}{ Output: } & Hot metal & 1000 & 1000 & 1000 \\
& Slag & 223 & 223 & 223 \\
& Exit gas & 3167 & 3512 & 4594 \\
\hline \multirow{2}{*}{ Total } & & 4390 & 4735 & 5817 \\
\hline
\end{tabular}

* Argon is from plasma torch.

$20 / 80$ as shown in Table 3. There were no reliable data on the slag quantity due to the coating of the slag on the refractory walls of the chamber, and no exit gas volume was measured in the experiment. The amount and composition of slag and exit gas were calculated based on the law of conservation of each chemical element and the given hot metal composition. The computed slag and exit gas compositions are listed in Tables 4 and 5, which are typical of the analyzed results. The exit gas composition was obtained upon the assumption of complete combustion except in case $\mathrm{A}$, where the excess air coefficient is less than the stoichiometric requirement.

Based on the results in Tables 3, 4 and 5, results of mass balance calculations per tonne of hot metal in these three cases are listed in Table 6.

\subsection{Heat Balance}

The dependence of energy efficiency of the process on excess air coefficient and productivity will become clear through heat balance calculations. Table 7 shows the heat balance based on the mass balance outlined in
Table 7. Heat balance (coal/ore $=20 / 80$ ). (For $1000 \mathrm{kgHM}$ at reference temperature $25^{\circ} \mathrm{C}$ )

\begin{tabular}{lrrrrrr}
\hline $\begin{array}{l}\text { Conditions } \\
\begin{array}{l}\text { Exc. air coef. } \\
\text { Prod. (kgHM/hr) }\end{array}\end{array}$ & $\begin{array}{c}\text { Case A } \\
0.92\end{array}$ & $\begin{array}{c}\text { Case B } \\
1.08\end{array}$ & \multicolumn{2}{c}{$\begin{array}{c}\text { Case C } \\
1.48\end{array}$} \\
\hline Items & $\mathrm{J} \times 10^{9}$ & $\%$ & $\mathrm{~J} \times 10^{9}$ & $\%$ & $\mathrm{~J} \times 10^{9}$ & $\%$ \\
\hline $\begin{array}{l}\text { Input: } \\
\text { Coal } \\
\text { heat }\end{array}$ & 12.13 & 64.44 & 12.13 & 75.13 & 12.13 & 58.59 \\
$\begin{array}{l}\text { Electric } \\
\text { heat }\end{array}$ & 6.69 & 35.56 & 4.02 & 24.87 & 8.58 & 41.41 \\
$\begin{array}{l}\text { Total } \\
\text { Output: }\end{array}$ & 18.82 & 100.00 & 16.15 & 100.00 & 20.71 & 100.00 \\
\hline $\begin{array}{l}\text { Reaction } \\
\text { heat }\end{array}$ & 6.61 & 35.12 & 6.61 & 40.93 & 6.61 & 31.92 \\
$\begin{array}{l}\text { HM \& slag } \\
\text { sens. heat }\end{array}$ & 1.84 & 9.78 & 1.84 & 11.39 & 1.84 & 8.89 \\
$\begin{array}{l}\text { Exit gas } \\
\text { sens. heat }\end{array}$ & 3.05 & 16.21 & 3.39 & 20.99 & 4.23 & 20.42 \\
$\begin{array}{l}\text { Exit gas } \\
\text { chem. heat }\end{array}$ & 0.75 & 3.99 & 0.00 & 0.00 & 0.00 & 0.00 \\
$\begin{array}{l}\text { Heat loss } \\
\begin{array}{l}\text { Total } \\
\hline\end{array}\end{array}$ & 6.75 & 34.90 & 4.31 & 26.69 & 8.03 & 38.77 \\
\hline
\end{tabular}

Table 6, with different feed rates established in the experiment.

Raw materials enter the furnace at ambient temperature. Slag and metal are assumed to leave the reactor at $1550^{\circ} \mathrm{C}$ and the temperature of the exit gas is $750^{\circ} \mathrm{C}$.

There are two sources in heat supply, i.e. the coal heat and the electric heat. At a fixed coal/ore ratio, the value of the coal heat is based on the calorific value of the coal, independent of the feed rate (about $370 \mathrm{~kg}$ coal/THM at coal/ore ratio of $20 / 80$ as shown in Table 6). For electric energy, the power input is constant in time and independent of feed rate. It is due to the fact that in this bench scale furnace, in order to maintain a stable plasma, the power has to be maintained constant. Hence, the electric energy input per unit mass of hot metal produced decreases with the increase of the productivity. If the sponge iron entering the melting chamber is at $1000^{\circ} \mathrm{C}$ with $90 \%$ metallization, without considering heat loss, the electric energy required is about $300 \mathrm{~kW}-\mathrm{hr} / \mathrm{THM}$.

Among items on the heat output side, the heat carried away by the exit gas is the only one which varies with the amount of excess air to be used.

In all three cases, the heat loss is very high in relation to total heat input. For a furnace of larger scale, it is anticipated that the heat loss would be significantly reduced.

For the reason of achieving a complete combustion, the volume of the exit gas from the LB Furnace is relatively large in comparison with that of the blast furnace. About $20 \%$ of total heat input is carried away from the furnace by the exit gas at a relatively high temperature. To recover sensible heat in the exit gas and improve energy efficiency of the whole process is an important subject in designing a large scale furnace, 
which has been discussed in detail in the Reference. ${ }^{10}$ )

Case $\mathrm{B}$, with the high productivity and the air input close to the stoichiometric requirement for complete combustion, shows the best energy efficiency among the three cases presented. The productivity of $15 \mathrm{~kg} \mathrm{HM} / \mathrm{hr}$ in Case $B$ corresponds to 88 tonne $\mathrm{Fe} / \mathrm{d} / \mathrm{m}^{3}$ based on the reduction tube volume and about $7 \mathrm{THM} / \mathrm{d} / \mathrm{m}^{3}$ based on the whole system. Case $\mathrm{A}$, with the air supply less than the stoichiometric requirement, results in an incomplete combustion, less heat released for the process, and increased chemical heat in the exit gas. In Case $\mathrm{C}$, where a large quantity of excess air is used, a large volume of the exit gas takes away a large amount of sensible heat from the system. In both Cases $\mathrm{A}$ and $\mathrm{C}$, the productivity is much lower than that in Case B and the electric energy consumptions are high.

\section{Conclusion}

A new ironmaking process based on the LB Furnace which has potentially technical and economic advantages, has studied through bench scale experimental work and process analysis. With direct use of the iron ore concentrate and pulverized coal as the raw materials, sponge iron, hot metal and slag were produced successfully.

The carbon content of the hot metal was in the range of 0.3 to $4.0 \%$. The behaviour of silicon and sulphur in hot metal are similar to that in blast furnace products. Sponge iron can be produced with a controlled degree of metallization depending on the furnace operation conditions.

The energy required for sponge iron production is supplied by coal, and in the bench scale experiment, for convenience, electric energy is used for melting. The complete combustion of the gaseous reduction product in one single reactor with high energy efficiency has been realized in this process. The technical feasibility of using the LB Furnace to produce liquid or solid iron at a much lower coal rate is confirmed. Under a typical condition in this study, coal consumption has been established to be $370 \mathrm{~kg} / \mathrm{THM}$ and the electric energy required is $300 \mathrm{~kW}-\mathrm{hr} / \mathrm{THM}$. Coal can also be the source of energy for melting if a metal bath is used as the melter.

The large specific areas and intimate contact of the reacting solids, the strong reducing power of the gas in the reduction tube, and the intensive heat transfer to the reacting mixture lead to the high reduction rate in the LB Furnace.

\section{REFERENCES}

1) R. B. Smith and M. J. Corbett: Proc. of 7th Process Technology Conf., ISS of AIME, Warrendale, PA, (1988), 147.

2) T. Inatani: Proc. of 50th Ironmaking Conf., ISS of AIME, Warrendale, PA, (1991), 651 .

3) E. Aukrust and K. Downing: Proc. of 50th Ironmaking Conf., ISS of AIME, Warrendale, PA, (1991), 659.

4) B. L. Cusack, G. J. Hardie and P. D. Burke: Presented at 2nd European Ironmaking Cong., TIM of UK, Glasgow, (1991)

5) H. M. W. Delport: Proc. of 2nd European Ironmaking Cong., TIM of UK, Glasgow, (1991), 289.

6) W-K. Lu: Presented at Ist Process Technical Conf., ISS of AIME, Washington D. C., (1980).

7) C. Bryk and W-K. Lu: Ironmaking Steelmaking, 13 (1986), 70.

8) C. Bryk and W-K. Lu: Can. Metal. Q., 25 (1986), 241.

9) W-K. Lu, C. Bryk and H. Gou: Proc. of 5th Int. Iron and Steel Cong., B-3, ISS of AIME, Warrendale, PA, (1986), 1065.

10) H. Gou: Ph. D. Thesis, Depart. of Materials Sci. and Eng., McMaster University, (1990).

11) W-K. Lu: Proc. of Int. Cong. on Physical Chemistry and Steelmaking, Versailles, France, (1978), 3.3.

12) H. Gou and W-K. Lu: Proc. of Process Technology Conf., ISS of AIME, Warrendale, PA, (1988), 271.

13) B. H. Huang, S. Sun and W-K. Lu: Presented at 3rd Canadian Materials Science Conf., Kingston, (1991). 